\title{
MELESTARIKAN KEARIFAN LOKAL BANJAR DENGAN MENGEMPLEMENTASIKAN ADAT BEUSUNG KHAS BANJAR KALIMANTAN SELATAN TERHADAP PESERTA DIDIK
}

\author{
Nisa \\ Email: 1910128220003@mhs.ulm.ac.id \\ Program Studi Pendidikan IPS Fakultas Keguruan dan Ilmu Pendidikan \\ Universitas Lambung Mangkurat
}

Banjarmasin

\begin{abstract}
ABSTRAK
Kebudayaan merupakan suatu tradisi yang tidak dapat dipisahkan oleh masyarakat dimana didalam lingkungan sosial terdapat banyak tradisi, masyarakat terbentuk adanya tradisi kalau tidak ada tradisi maka suatu masyarakat tidak terjalin ataupun sebaliknya jika tidak ada masyarakat maka tidak ada yang menjalankan tradisi. Di Kalimantan selatan memiliki banyak budaya lokal yang masih dilestarikan oleh orang atau masyarakat tertentu, satu diantara kearifan lokal banjar yang masih di jalankan satu diantaranya adat beusung, adat ini sering dilakukan oleh para penganten banjar yang satu diantara penganten tersebut sudah mempunyai adat turun temurun untuk mengerjakan tradisi tersebut, jikalau penganten yang masih ada keturunan tersebut tidak melaksanakan adat beusung maka penganten tersebut bisa kesurupan karena tidak melaksanakan kegiatan tradisi beusung. Jika dikaitkan kearifan lokal, adat beusung ini terhadap pendidikan maka dapat dijadikan sebuah implementasi pembelajaran dimana peserta didik dapat mendengar serta mengetahui kearifan lokal yang ada pada kearifan lokal suku banjar maka dari itu didalam tulisan ini saya akan meuraikan serta menjelaskan melestarikan kearifan lokal adat beusung dengan mengenalkan kepeserta didik didalam pembelajaran.
\end{abstract}

Kata Kunci: Adat Beusung, Kearifan Lokal, Suku Banjar, Pendidikan. 


\section{PENDAHULUAN}

Kalimantan Selatan merupakan satu diantara provinsi yang ada di Indonesia. Dimana Indonesia memiliki banyak suku-suku satu dianataranya suku banjar yang mempunyai tradisi yang dimana disana memili suatu tradisi acara pernikahan yakti tradisi beusung. Beusung merupakan satu diantara budaya yang unik dimana disana tumbuh dan berkembangnya di Kalimanatan Selatan. Beusung di ambil dari kata Usung yang bermakna gendong yakni sepasang pengantin sebelu mereka disandingngkan dipelaminan di saat mempelai pria datang kerumah mempelai wanita. Di laksankaannya lah adat beusung itulah kedua mempelai di gendong ke dua mempelai di saksikan oleh para tamu serta undangan yang berhadir langsung dilakukanlah oleh si pengusung atau si pengngkat tersebut dengan kedua tangan mereka lalu si kedua mempelai tersebut diangakat sambil menari-nari berkeliling di iringin oleh musik dan dua penari sambil menggendung atau mengangkat si kedua mempelai yang disaksikan oleh para tamu undangan yang berhadir, lalu setelah itu laki-laki pertama mengusung mempelai pria dan laki-laki ke dua mengusung mempelai wanita, dari laki-laki yang mengusung kedua memelai di tentukan harus kuat fisik agar mmapu menahan beban dari berat kedua mempelai, mempelai ria duduk di atas bahu dengan posisi mengangkang sedangkan memelai wanita duduk dengan posisi menyamping.

Pada mulanya beusung itu hanya bisa dilakukan oleh beberapa golongan saja satu diantaranya suku bajar atau lenbih dapat dikenal dengan keluarga yang ekonominya lebih atas sehingga ketika sebuah keluarga mengadakan acara beusung dapat dianggap keluarga itu keluarga mampu dikarenakan mampu mengadakan acaranya selain itupun juga dianggap sebagai acara adat yang sangat mewah. Terhadap perkembanganna tradisi besung inipun juga tidak lagi menjadi pesta pada kalangan orang kaya namun sudah menjadi hibuan bagi masyarakat yang ada di sana atau masyarakat setempat pada setiap acara pernikahan tersebut. Bagi masyarakat banjar yang melaksanakan pernikahan belum semurna kalau tidak melaksanakan beusung, bahkan ketika masyarakat banjar yang merantau ke daerah lainpun itu dan ada juga masih banyak adat ini dapat dipakai didalam peserta pernikahan didaerah rantauan satu diantaranya yakni masyarakat suku banjar yang ada di kabupaten indragini hilir provisi riau. Handuwa(2010) didalam artikelnya"Mengusung Budaya Banjar" yang menyatakan bahwa orang tua dulu ketika 
gunun Krakatau di selat sunda meletus sekitaran abad ke-18 komonitas suku banjar di kawasan ini meruakan bukan tujuan tembilan di riau melainkan kebatu pahat Malaysia.

Adapun juga suku banjar yang kebanyakannya eksodos ke Sumatra tersebut dapat berasal dari desa kelua, sungai turak, karias, sungai durian, hulu sungai utara dan lainnya setelah eksodos ke batupahat terus bertambahhh akhirya masyarakat suku banjar ini mulai dapat menyebarkan ke kakawasan lainnya yang dianggap dapa memberikan penghidupan baru dan akhirnya pilihan suku banjar di perantauan ini juga jatuh ke wilayah sapat indagiri hilir dapat karena ala yang aa ddi sekitar ini tidak jauh beda dengan Kalimantan selatan yakni rawa-rawa pasang surut bagi etnis lain sulit akan menggarap lahan semacam itu kecuali terampilan dalam menggarap suku banjar asal Kalimantan selatan maupun bugis asal Sulawesi selatan. Singkat cerita berdasarkan perkembangan sejarah tersebut penyebaran suku banjar di wilayah Indragiri hilir sangat berkembang pesat, begitu juga dengan seni pertunjukan atau beusung yang didalamnya terdapat pada iringan-iringan pada adat beusung.

Pada era reformasi ini dimana setiap daerah telah memberikan ruang serta kesempatan kepada setiap daerah untuk dapat mengembangkan dan mempertahankan kebudayaan dan juga mengembangkan nilai-nilai kearifan lokal dan sejarah kkebudayaanya selama hal tersebut tidak bertentangan dengan prinsip dasar yang tergantung dalam nilai-nilai sosialnya dan juga dapat melestarikan kearifan lokal yang ada disekitar agar tidak tergerus dengan zaman yang semakin canggih dan modern.

\section{MELESTARIKAN KEARIFAN LOKAL BANJAR DENGAN MENGEMPLEMENTASIKAN ADAT BEUSUNG KHAS BANJAR KALIMANTAN SELATAN TERHADAP PESERTA DIDIK}

Beusung merupakan satu diantara tradisi pernikahan yang ada di Kalimantan selatan, yang mana cara pelestariannya dengan selalu mengadakan tradisi beusung ketika ada sepasang orang yang ingin menikah lalu di resepsinya dilaksanakanlah beusung setelah itu pada zaman dahulupun juga tradisi beusung ppengantin hanya dapat dilaksankan oleh kalangan orangkaya yang berada yang memiliki perekonomian yang besar dan melimpah dan juga bisa dapat dibilang memiliki banyak uang dan dapa mengadakan acara yang besar. Seiring berkembnagnya zaman maka tradisi beusung ini 
tidak dilakukan oleh kalangan bangsawan tetapi adat ini bisa juga dilakukan oleh kalangan yang menengah atau sudah jbisa dilakukan oleh kalangan orangbanyak atau seluruhnya sudah bisa melaksanakan tradisi tersebut pada saat mengadakan resepsi pernikahan.

Pengemplementasikan suatu tindakan-tindakan yang dilakukan pada suatu proses yang diadikan sebuah kebiasaan yang dilakukan pada saat resepsi pernikahan yang didalanya terdapat tradisi beusung setelah itu adapun juga prosesnya yakni satu diantaranya basasuluh atau bisa disebut juga dengan awal pernikahan terhadap calon mempelaiwanita dan keluarga, betatkunan ini biasanya ini ketahap yang lebih serius dan mendalam adapun juga badatang lalu mentar jujuran setelah itu maantar patalian, menatar jujuran dan terakhir menikah setelah menikah ada tahaannya lagi badandan, setelah itu batimung, adapun juga proses bepacar, lalu mandi-mandi. Lalu di adakannya lah tradisi beusung itu dengan tradisi-tradisi yang tentuna berbeda-beda setiap daerahnya .

Sebagai adat istiadat, bausung pengantin menjadi sebuah kewajiban yang tak boleh ditinggalkan oleh Suku Banjar. Mitosnya, jika meninggalkan akan mendapatkan sanksi berupa kerasukan dan kepingitan. Masyarakat yang masih memegang erat tradisi ini selalu mengamalkan dan mewariskannya. Perubahan tradisi selalu terjadi seiring akibat perkembangan zaman. Tradisi bausung pengantin sudah mengalami perubahan dalam hal aturan, alat-alat yang dipakai, serta para 'pemeran'nya. Dulu, bausung pengantin dilakukan sebanyak dua kali yaitu pada saat turun mandi pengantin dan turun ke pelaminan. Kini cukup dilakukan sekali saja. Jika tradisi bausung dahulu diiringi musik gamelan dan gong kerajaan, sekarang cukup dengan menyalakan musik gamelan dari music player atau bahkan tanpa musik. Adat istiadat bausung pengantin penting untuk dilestarikan dan dijaga sebagai warisan dari nenek moyang. Karena ini merupakan peninggalan yang sangat berharga dan yang menjadi cirri khas pada suatu daerah atau sebuah suku.

Adapun juga pesen yang dapat diemplementasikan terhadap pendidikan yakni satu diantaranya yakni peserta didik dapat mengetahui apa kearifan lokal yang ada di banjar dan nilainya dari kearifan lokal pada pembelajaran dimana peserta didik dapat mendengar serta mengetahui kearifan lokal yang ada pada kearifan lokal suku banjar 
maka dari itu didalam tulisan ini saya akan meuraikan serta menjelaskan melestarikan kearifan lokal adat beusung dengan mengenalkan kepeserta didik didalam pembelajaran.

\section{KESIMPULAN}

Pada kesimpulannya kearifan lokal Bausung adalah salah satu budaya unik yang tumbuh dan berkembang di Kalimantan Selatan. Bausung diambil dari kata Usung yang bermakna gendong. Yaitu Sepasang Pengantin sebelum mereka bersanding di pelaminan (saat mempelai pria datang ke rumah mempelai wanita) dilakukanlah adat bausung. Bausung dilakukan oleh dua penari yang dïringi dengan musik Banjar, kedua penari menggendong kedua mempelai disaksikan oleh para tamu dan undangan yang hadir menuju pelaminan. Pada awalnya bausung hanya dilakukan oleh beberapa golongan saja dalam suku Banjar atau yang lebih dikenal dengan keluarga ekonomi kelas atas, sehingga ketika sebuah keluarga mengadakan acara bausung dianggap bahwa keluarga itu tergolong dari keluarga yang mampu, selain itu bausung juga dianggap sebagai acara adat yang mewah. Namun pada perkembangannya, tradisi bausung ini tidak lagi menjadi pesta pada kalangan orang kaya saja, namun sudah menjadi hiburan bagi masyarakat setempat pada setiap acara pernikahan, bahkan ketika orang Banjar merantau ke daerah lain. 


\section{DAFTAR PUSTAKA}

Abbas, E. W. (2015). Pendidikan IPS Berbasis Kearifan Lokal. WAHANA Jaya Abadi.

Abbas, E. W. (2018). Penguatan Pendidikan IPS Di Tengah Isu-Isu Global.

Ade, T. (2018). Analisis Musik Silat Pengantin (Bausung) Di Kecamatan Tembilahan

Adhawiyah, R. (2019). Nilai-nilai pendidikan islam pada upacara adat perkawinan dayak bakumpai di Kabupaten Barito Utara (Doctoral dissertation, IAIN Palangka Raya).

Azizah, N. (2021). TRADISI BAUSUNG DALAM PERSPEKTIF ANTROPOLOGI DI PEMBELAJARAN IPS.

Ihsan, I. (2014). Strategi guru pendidikan agama Islam dalam menanamkan nilai-nilai multikultural di SMP Negeri 1 Kota Bima (Doctoral dissertation, Universitas Islam Negeri Maulana Malik Ibrahim).

Kabupaten Indragiri Hilir Provinsi Riau (Doctoral dissertation, Pendidikan Sendratasik). Afandi, R. (2011). Integrasi pendidikan karakter dalam pembelajaran IPS di sekolah dasar. PEDAGOGIA: Jurnal Pendidikan, 1(1), 85-98.

Muchtar, K., Koswara, I., \& Setiaman, A. (2016). Komunikasi antar budaya dalam perspektif antropologi. Jurnal Manajemen Komunikasi, 1(1). 